\title{
La dualidad humana en los cuentos mexicanos de Max Aub y Lluís Ferran de Pol
}

\author{
María Jesús PiñeIRo DomíngueZ \\ Universidad de A Coruña \\ mpineiro@udc.es \\ Recibido: mayo del 2011. Aceptado: julio del 2011.
}

\begin{abstract}
Resumen: El estudio pretende llevar a cabo un análisis temático y estructural de algunos de los cuentos de los escritores Max Aub (1903-1972) y Lluís Ferran de Pol (1911-1995), que estuvieron exiliados en México. En las obras Crímenes ejemplares y La ciutat $i$ el tròpic los personajes experimentan constantemente la realidad subyacente de la muerte; y esta acentúa el carácter dual de la persona, que se ve sometida a constantes tensiones existenciales. México, la muerte y la dualidad humana son los tres ejes que articulan este estudio.
\end{abstract}

Palabras clave: exilio, cuentos mexicanos, dualidad, alienación, México, muerte, sujetos divididos.

\begin{abstract}
The aim is to carry out a thematic and structural analysis of some of the stories of the writers Max Aub (1903-1972) and Lluís Ferran de Pol (1911-1995), who were exiled in Mexico. In Crímenes ejemplares and La ciutat $i$ el tròpic the main characters constantly experience the underlying reality of death; and this underscores the dual nature of people, who are subjected to constant existential tensions. Mexico, death and human duality are the three main topics of this analysis.
\end{abstract}

Keywords: exile, Mexican stories, duality, alienation, Mexico, death, split subjects.

\section{INTRODUCCIÓN}

Los escritores Max Aub (1903-1972) y Lluís Ferran de Pol (1911-1995) compartieron, además de vocación literaria, destino y experiencias: la Guerra Civil española, la estancia en campos de concentración y el posterior exilio mexicano. Durante su exilio en México, sus creaciones literarias absorbieron el impacto que este país causó en sus trayectorias personales y profesionales; y sus obras, de una forma u otra, se vieron influenciadas por esta cultura. 
El objetivo de este estudio ${ }^{1}$ es la comparación temática y estructural de dos de sus obras más representativas: Crímenes ejemplares, de Max Aub, y La ciutat $i$ el tròpic, de Lluís Ferran de Pol. Para ello partimos de una estructura triangular que nos permitirá articular el análisis: México, la muerte y las dualidades humanas. Así, el punto de partida es la revelación de la condición dual del hombre, quien dentro de un contexto físico (México) experimenta la realidad subyacente de la muerte.

En los dos casos el cuento es el medio escogido para transmitir de manera breve, concisa y directa la realidad de unos personajes sometidos a constantes oposiciones binarias. Las dos recopilaciones de cuentos ejemplifican cómo aflora la dualidad humana —un concepto formulado por Platón (1991), que considera que la naturaleza humana está dividida en cuerpo y alma, siendo uno cárcel del otro- y revela los instintos más primarios del hombre.

Dentro del panorama literario peninsular, el cultivo del cuento experimentó un auge significativo gracias a las propuestas de Aub y de Ferran de Pol. En estas breves narraciones - brevísimas en el caso de Aub- se manifiesta el carácter mexicano y se muestra la recepción de su cultura por parte de quienes son ajenos a ella. La muerte se convierte en compañera inseparable, y la revelación de la dualidad humana transforma a los personajes en sujetos divididos (Eagleton 1988).

En La Ciutat i el tròpic el escritor catalán exprime al máximo las consecuencias del choque de culturas, que se reflejan en los cinco cuentos que componen la obra. Sus personajes, atrapados entre la naturaleza y la civilización, se entregan a decisiones existenciales, al contrario que los protagonistas de Crímenes ejemplares, cuya lógica se revela grotesca y absurda. Las escuetas narraciones de Aub están ambientadas en tierras mexicanas, o influenciadas por ellas de alguna manera; la muerte es común en todos los cuentos y se presenta en forma de crimen, suicidio, enfermedad o viaje.

La estructura triangular propuesta para la realización de este estudio - México, muerte y dualidad - no solo será útil para la comparación temática y estructural de las dos obras, sino para extraer unas conclusiones que se recogerán en el apartado final y que evidenciarán la aparición de un sentimiento de alienación que condiciona la vida y la muerte de los personajes.

\section{CONTEXTUALIZACIÓN Y ESTRUCTURA NARRATIVA}

Lluís Ferran de Pol recibió el premio Víctor Català por La ciutat $i$ el tròpic, una recopilación de cinco cuentos escrita en 1956, que narra el choque de civilizaciones. El escritor catalán vivió diez años en México, exiliado a causa de la Guerra Civil, y durante ese tiempo estudió Letras y fue crítico de arte. El arte es

${ }^{1}$ Este estudio forma parte de un trabajo de doctorado correspondiente al curso «Estudio comparado de la narrativa ibérica contemporánea», impartido en la UDC por la Dra. Olivia Rodríguez González en 2007. 
un factor clave en su obra, y en el país mexicano quedó impresionado por la obra de Diego Rivera, así como por la lucha entre el carácter autóctono y la imposición colonial.

Regresó a Cataluña en 1948 y al poco tiempo comenzó a escribir esta obra que incorpora algún trazo autobiográfico y que denota la influencia de la corriente existencialista de la época. La presencia del mito es recurrente, y se utiliza para ejemplificar las dualidades que acompañan a las personas a lo largo de su vida y que las atrapan en una encrucijada de oposiciones binarias. Los cuentos de La ciutat i el tròpic destilan un tono fatalista. El destino es implacable y provoca en las personas angustia y frustración. Los personajes no pueden escapar a lo que está determinado, y la vida se plantea como una condena. El fracaso y la desesperación marcan el ritmo de las narraciones; la cultura occidental queda anulada por el trópico y por el enfrentamiento barbarie-civilización.

La primera historia, «Suïcidi a la matinada», es una reflexión sobre la inadaptación existencial y la incapacidad de asimilación del éxito repentino. El suicidio de un fotógrafo de prestigio conmociona a todos. Tras una infancia de miseria y delincuencia, el salto a la fama y un encuentro casual con Diego Rivera causan en él una frustración vital de la que nunca podrá recuperarse. El fotógrafo asume su falta de originalidad y sus carencias creativas, y contempla su trabajo como una simple copia de la realidad. Su angustia vital transcurre paralela a su ascenso profesional, y la fotografía se convierte en una cárcel para él. El suicidio culminará su proceso de autodestrucción.

El segundo cuento, «El centaure i el cavaller», es el más largo de los cinco y emplea la mitología de una forma más explícita. El personaje principal es un joven huérfano que emigra a México en busca de una oportunidad personal y profesional. Allí encuentra trabajo en un picadero. Ante la llegada de otro picador junto a su esposa, estalla la tensión. El joven experimenta una atracción por la esposa y sufre la amenaza que supone la competencia, tanto para el negocio como para su vida personal. Para el joven picador, la única forma de resolver el conflicto será el asesinato del recién llegado.

«La lletra» es el tercer cuento de La ciutat $i$ el tròpic y en él se recrea la metáfora del sueño americano a través del despertar de un personaje. La pasividad de un hombre abandonado por segunda vez se transforma en iniciativa cuando emigra a México junto a su hijo en busca de una nueva oportunidad. Al llegar, el negocio para el que han sido recomendados se encuentra en liquidación. Sin embargo, ante este nuevo revés, padre e hijo colaborarán en el cierre de la tienda. Ferran de Pol sitúa a sus personajes en una situación absurda y resalta la forma en la que las personas logran reaccionar, por fin, ante la vida.

En el cuarto cuento, «Jungla», la representación del absurdo llega a cotas máximas, lo que recuerda al estilo de Aub. Un periodista que ha roto, de nuevo, la relación con su novia sale a tomar unas copas con un compañero de profesión, con la única intención de evitar disculparse con ella. Durante su salida, se intercalan las reivindicaciones políticas del acompañante con los pensamientos obsesivos del periodista sobre su pareja. Tras la entrada de un diputado en el bar, se produce un tiroteo y el compañero muere por el fuego cru- 
zado. El asesinato recae sobre el joven periodista, quien se alegra de tener un motivo real para no realizar esa llamada de reconciliación. Ferran de Pol denuncia a través de este doble plano narrativo la realidad del caciquismo mexicano y para ello recurre al absurdo, al estilo de muchas novelas norteamericanas de entreguerras.

El último cuento de la serie, titulado «Naufragis», está considerado como una aproximación autobiográfica, en palabras del propio Ferran de Pol (Busquets 1979). El personaje principal es un estudiante de cuarto curso de Medicina que sufre las agonías de la guerra española y de un campo de concentración francés. El joven viaja a México para luchar contra las fiebres amarillas y experimenta la dureza de su trabajo, unida al rechazo de muchos compañeros. Allí conoce a una mujer de ascendencia francesa con la que establece una relación. Tras una serie de circunstancias, el joven es denunciado por otros médicos y se le condena a ejercer sin título en una tierra ajena. La pareja sufre un choque cultural que les produce un desarraigo y un desajuste de la identidad. Ferran de Pol ejemplifica la alienación de los exiliados en la tierra de acogida y las consecuencias del intrusismo occidental en el trópico.

El exilio mexicano de Max Aub fue bastante más largo que el de Ferran de Pol, y quizá más doloroso debido al doble refugio al que tuvo que acogerse el escritor de origen francés. Obligado a exiliarse en España durante la I Guerra Mundial, sufrió un segundo exilio tras el estallido del conflicto español. Al igual que Ferran de Pol, estuvo recluido en campos de concentración y, finalmente, llegó a México en 1942, donde residió hasta su muerte en 1972.

Comenzó a publicar algunos de sus crímenes a finales de la década de 1940 en su revista personal Sala de Espera. Algunos de ellos se recogen solamente en algunas ediciones, al igual que el prólogo y la «Confesión», fruto de las revisiones del autor. La edición que se maneja ${ }^{2}$ en este estudio consta también de los apartados llamados «De suicidios», «De gastronomía», «Epitafios» y de un anejo con los crímenes que suprimió el autor en la edición de 1968, además de dos «Crímenes barrocos».

Crímenes ejemplares es una recopilación de cuentos (o microrrelatos) cuyo nexo es el asesinato y el suicidio. Los cuentos están narrados en clave de humor negro y giran en torno a la intolerancia del ser humano, su impaciencia y la aceptación de su naturaleza violenta, hasta llegar a la justificación de sus actos. Las influencias literarias presentes en la obra han sido admitidas por el propio Aub en la «Confesión». Destacan las greguerías de Gómez de la Serna o la sátira de Quevedo. Además, la utilización del absurdo y del esperpento remite a Valle Inclán. Por otro lado, el existencialismo francés, con Camus a la cabeza, también ha influido en Aub, como sucedió con Ferran de Pol. Así, el significado de la vida y de la muerte es un tema recurrente en ambos autores.

Para analizar la estructura de Crímenes ejemplares se proporcionarán algunos ejemplos ilustrativos de cada apartado. La brevedad de los microrrelatos a veces resulta extrema, casi sentenciosa, y concentra en pocas líneas toda una es-

\footnotetext{
${ }^{2}$ Edición de Espasa, 1999.
} 
tructura narrativa. Aub maneja el lenguaje de forma magistral y emplea recursos retóricos como la elipsis, la hipérbole o los juegos de palabras para narrar los crímenes de esa manera tan escueta (Arranz, 2003).

El título es un guiño al lector; la paradoja crimen-ejemplar sin duda llama la atención por lo ilógico de su formulación. En la primera sección de Crímenes ejemplares, llamada «Confesión», el autor reconoce sus influencias literarias y proclama con ironía la intención de su obra: «A lo mejor, inconscientemente, éste es un libro político, pero no creo que pase de ser un homenaje a la confraternidad y a la filantropía». En el prólogo, Aub juega nuevamente al desconcierto y expone su estilo narrativo, sus fuentes de inspiración, la forma de obtener las informaciones: «Reconozco que, para hacerles hablar sin prejuicios, recurrimos [...] a cierta droga hija de algunos hongos mexicanos...»; y manifiesta su opinión sobre los crímenes y sobre los asesinos. Max Aub muestra su ambigüedad al admitir la espontaneidad y la sinceridad de los asesinos: «Ingenuamente dicen - a mi ver - verdades», al mismo tiempo que critica, con ironía, «la mediocridad de aquellos que contienen sus impulsos».

Los argumentos de los crímenes de Aub son muy diversos. Los narradores son hombres y mujeres que informan al lector, a través de un breve monólogo o mediante diálogos-, sobre los motivos que les llevaron a cometer el crimen. En todos los casos, justifican sus acciones convirtiendo a la víctima en culpable de sus arrebatos criminales, aunque la falta de premeditación produce una gran satisfacción en el asesino. El lector desempeña un papel importante en la lectura, ya que, ante la inexistencia de un contexto narrativo, se encuentra cara a cara con la narración del asesino en primera persona y debe deducir la existencia de un asesinato y sus circunstancias mediante la explicación del criminal. Los narradores se dirigen al lector, a una audiencia indefinida, o al juez ante el que comparecen. Algunos ejemplos son:

ERA TAN FEO el pobre, que cada vez que me lo encontraba, parecía un insulto. Todo tiene su límite.

DE Mí NO SE RíE nadie. Por lo menos, ése ya no.

LE OLíA el aliento. Ella misma dijo que no tenía remedio...

¡Tenía el cuello tan largo!

ES QUE USTEDES NO SON mujeres, y, además, no viajan en camión, sobre todo en el Circunvalación, o en el amarillo cochino de Circuito Colonias, a la hora de la salida del trabajo. Y no saben lo que es que la metan a una mano.

[...] me llevé un cuchillito, filoso, eso sí. Sólo quería pincharle. Pero entró como si fuera manteca, puritita manteca de cerdo. Era otro, pero se lo merecía igual que aquél.

La sección de suicidios es igualmente sentenciosa. Se componen, en su mayor parte, de una o dos líneas y, en algún caso, forman un párrafo. La técnica de la elipsis domina la narración, al igual que en los crímenes, y el lector debe interpretar la lectura. Algunos ejemplos de suicidio son: 


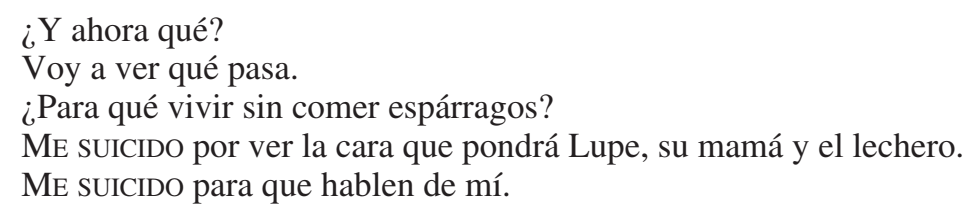

La sección de «Gastronomía» es, en realidad, una recopilación de crímenes antropófagos, narrados con un estilo grotesco e impactante:

No hay nada como comer el ojo del enemigo. Revienta entre las muelas como granote de uva, con gustito de mar.

Los epitafios recuerdan a la literatura satírica de los siglos de oro y se clasifican según su destinatario:

De un tirano:
Fue a lo suyo
por lo tuyo.
De un imbécil:
A todo dijo que sí.

Por último cabe destacar que, en el anejo, los crímenes suprimidos en la edición de 1968 y los dos crímenes barrocos finales siguen la misma estructura que los anteriores y poseen características similares.

Las diferencias estructurales que existen entre los cuentos de Ferran de Pol y los breves relatos de Aub son evidentes. Las cinco narraciones de La ciutat i el tròpic son historias relacionadas entre sí pero independientes, y pueden entenderse fuera de contexto. Eso no sucede con los microrrelatos de Crímenes ejemplares, que necesitan de inferencias para su comprensión. Los relatos del escritor catalán pueden adscribirse al género del cuento, e incluso hay uno, «El centaure i el cavaller», que puede considerarse como una novela corta. Sin embargo, la clasificación de las obras de Aub suele ser complicada debido a su afición por la fusión de géneros: novelas teatralizadas, guiones novelados, o colección de microficciones realísticas (García Sánchez, 2006: 21), como en el caso de Crímenes ejemplares. Ambos escritores recurren al absurdo, sobre todo Aub, para construir unos relatos ambiguos, paradójicos, grotescos, llenos de equívocos y de giros argumentales y, principalmente, ambientados en tierras mexicanas, con la muerte recordando a los personajes la insignificancia de sus vidas.

\section{MÉXICO}

Indudablemente, México es uno de los aspectos que unen a Ferran de Pol y a Aub debido al exilio mexicano que vivieron. En el caso del escritor catalán, el país dejó en él una profunda huella. Allí fundó las revistas Full Català y Quaderns de l'exili, y publicó varios artículos. A su regreso a Cataluña en 1948 reanudó su producción narrativa. Al contrario que los personajes de sus cuentos, 
Ferran de Pol se integró plenamente en el país. Tras su regreso a Cataluña, quiso expresar su fascinación por la cultura maya y azteca, y transmitir al mismo tiempo sus impresiones acerca del choque entre la civilización y la naturaleza. Tal y como explica Jordi Castellanos (1995: 25) en el prólogo de la edición comentada de La ciutat $i$ el tròpic, el trópico engulle a la ciudad.

La presencia de México es fundamental en casi toda la obra de Ferran de Pol y forma parte de su narratividad. En este país se sitúan los cinco cuentos de $L a$ ciutat $i$ el tròpic. La alusión a las ciudades mexicanas es constante: Tampico, Veracruz, Ciudad de México, etcétera. Además, México actúa como un factor condicionante que transforma las vidas de los personajes. Estos son, en su mayoría, occidentales, y reflejan el efecto que la cultura del trópico causa en ellos. México absorbe sus vidas y ellos no pueden asimilar su influencia.

En el primer cuento, «Suïcidi a la matinada», México aparece representado en la figura de Diego Rivera, con quien el fotógrafo tiene un encuentro que marca el inicio de su ascenso profesional y el de su declive personal. El fotógrafo asume su incapacidad de creación al estilo del gran pintor, y no es capaz de asimilar sus propias dotes artísticas — que él denomina «copias»—, adquiridas por casualidad — tras robar una cámara-, ni es capaz de apreciar el reconocimiento del público. El fotógrafo queda fascinado por Diego Rivera y decide retratar la belleza como una perversión íntima del que colecciona momentos atrapados en el tiempo y en el espacio, como un asesino de cosas bellas: «La pintura crea quelcom que no existia, la fotografia mata tot el que se li posa al davant». La fama adquirida le conduce hacia la autodestrucción y se suicida, superado por su propia infravaloración. Rivera es el máximo exponente de México en este cuento, y actúa como un revulsivo que condena al fotógrafo a la decadencia.

En «El centaure i el cavaller», Ferran de Pol muestra la dureza de las condiciones de vida en la tierra de acogida, donde cualquier amenaza se percibe como una afrenta personal que debe solucionarse a la manera tradicional, es decir, mediante el asesinato. La justicia del trópico se revela como la más efectiva ante el conflicto. México saca a relucir los instintos más primarios del hombre; representa la lucha y la competitividad llevadas al extremo. El recién llegado picador ejerce el papel de colonizador derrotado por aquellos que han asimilado la cultura de la barbarie como propia. La identificación con la tierra es total, y el joven picador, desde su llegada, aprende a no sucumbir ante las amenazas, una virtud propia — según él— de los mexicanos. El asesinato de quien no es bienvenido adquiere sentido - e incluso pretende justificarse - cuando abre la puerta a una nueva vida a todos los personajes, que han favorecido el enfrentamiento.

El mito americano se deja entrever en «La lletra». México es, en esta ocasión, la tierra prometida, que motiva el despertar de un carácter adormecido. Paralelamente, la tierra mexicana representa el desengaño y la superación de la adversidad. Durante su aventura mexicana, el padre y el hijo sufren la realidad del desamparo. Sin embargo, México ejerce una fascinación en el padre, ya que le brinda una oportunidad de libertad e independencia tras una vida de dependencia afectiva. En esta ocasión, la cultura mexicana representa una puerta abierta a la esperanza. El viaje resulta liberador para el padre; y su llegada a México, pese a la desilusión inicial, se percibe como una experiencia positiva. La diferencia ra- 
dica en la actitud del recién llegado, quien no actúa como colonizador sino como huésped. Solo entonces, México deja de ser un lugar inhóspito y se convierte en una tierra de acogida.

En «Jungla», los dos planos narrativos se desarrollan en un contexto tan agresivo como el propio título del cuento. México es exotismo y también es corrupción caciquil. El trópico —el cabaret «La Jungla»— es el escenario de las tensiones políticas y personales de los personajes; un lugar donde reina la confusión y donde la justicia es arbitraria. En esta ocasión, Ferran de Pol resalta las deficiencias democráticas del país. El cuento adquiere un tono político que denuncia la arbitrariedad de la justicia y México se muestra como una tierra caótica, asilvestrada y políticamente subdesarrollada.

«Naufragis» es la expresión máxima del choque de culturas. En México, los sentimientos más violentos afloran en medio de la desesperación. Las fiebres amarillas, las envidias entre occidentales y el rechazo de los indios construyen un contexto extremo en el que se mueven los personajes. La pérdida de identidad es la primera y más grave consecuencia de la estancia en México del médico pregraduado. Su dedicación a la medicina le hace olvidar su ascendencia, hasta que encuentra a una joven que también «es de allí». En este caso, México provoca la alienación de los occidentales. El allí y el aquí les condenan a vivir resignados, apartados y siempre rodeados de muerte.

Volviendo a Max Aub, en Crímenes ejemplares la presencia de México es más lingüística que contextual. Ante la falta de una trama argumental esclarecedora, debemos remitirnos al léxico empleado y a los lugares mencionados en los brevísimos cuentos para justificar su relación con el país mexicano. Los microrrelatos de Crímenes ejemplares son una recopilación de anécdotas recogidas en varios lugares y en diferentes épocas; estas historias, según su autor, carecerían de nacionalidad porque representan la naturaleza humana, tal y como afirma en el prólogo: «Un siciliano, un albanés mata por lo mismo que un dinamarqués, un noruego o un guatemalteco». Sin embargo, es inevitable su vinculación con el país mexicano. Por un lado, el largo exilio de Aub en México lo sugiere. Además, la proliferación de léxico mexicano es constante: «Les dábamos en toditita la madre a esos chingones de la Nopalera» $\mathrm{u}$ «iHola mano!». Este ejemplo todavía es más claro:

¡ERA SAFE, señor! Se lo digo por la salud de mi madrecita, que en gloria esté... Lo que pasa es que aquel ampáyer la tenía tomada con nosotros. En mi vida he pegado un batazo con más ganas. Le volaron los sesos como atole con fresa...

Algunas localizaciones no dejan lugar a dudas y corresponden a Ciudad de México. Las ubicaciones también se observan en el ejemplo mencionado anteriormente sobre la mujer acosada, que viaja en «el Circunvalación, o en el amarillo cochino de Circuito Colonias». Otros ejemplos son:

ERA IMBÉCIL. Le di y expliqué la dirección tres veces, con toda claridad. Era sencillísimo: no tenía sino cruzar la Reforma a la altura de la quinta cuadra... 
Me había citado a las siete y cuarto en la esquina de Venustiano Carranza y San Juan de Letrán.

Según algunas opiniones, es arriesgado afirmar que México es el escenario de los crímenes y que los asesinos son mexicanos en su mayor parte. Así, el estudio de Juan Carlos Hernández Cuevas (2004) apuesta por la mexicanidad de Crímenes ejemplares, basándose en un estudio previo de Samuel Ramos (1963); mientras que el análisis de Javier Sánchez Zapatero (2007) defiende su internacionalidad. Sin embargo, en este análisis se considera que México es un vínculo entre Aub y Ferran de Pol, y se estudia el reflejo del país en ambos autores. Los microrrelatos de Aub, por tanto, participarían de esta influencia, a pesar de la dificultad de su ubicación. Es cierto que, a la hora de relacionar los crímenes con México hay que remitirse casi exclusivamente a los criterios lingüísticos, ya que la falta de desarrollo narrativo impide contextualizarlos. Pero el exilio mexicano del autor aporta un sustrato mexicano a su obra, y va más allá de un léxico que, efectivamente, podría haber utilizado para narrar otro tipo de cuentos. Por extensión, tomando ejemplos de otras obras, como Cuentos mexicanos, no sería difícil hablar de un acercamiento natural entre Crímenes ejemplares y México, el cual no resultaría tan forzado (Sánchez, 2007).

Así, la ausencia de trama narrativa, la falta de contextualización y la autoproclamada universalidad de los crímenes por parte del autor no justificarían su exclusión del repertorio mexicano de Aub. Los personajes de Ferran de Pol son, en su mayor parte, occidentales situados en México que experimentan la influencia de los trópicos en sus vidas; por esa regla de tres, en Crímenes ejemplares la nacionalidad de los asesinos no sería incompatible con la aceptación de un trasfondo mexicano que está implícito más allá del léxico empleado o de la situación de exiliado del autor, y que se deja entrever, por ejemplo, en la cotidianidad de la muerte.

\section{LA MUERTE}

La muerte está presente en todos los cuentos y es otro de los temas que comparten Ferran de Pol y Aub. La muerte es un personaje más y aparece en todos los contextos, en forma de suicidio, asesinato o enfermedad, y casi siempre ejerce una función liberadora para alguien.

Hay que resaltar las diferencias culturales que existen entre la civilización mexicana y la europea con respecto a la muerte. La muerte en el contexto del trópico posee un significado muy distinto al que están acostumbrados los europeos. La muerte es algo cotidiano, y cualquiera tiene el derecho de practicarla sobre los demás o sobre sí mismo, y así lo manifiesta Aub en Crímenes ejemplares, donde constantemente los personajes se toman la justicia por su mano. Ferran de Pol, por su parte, introduce el tema de la cotidianidad de la muerte en las vidas de todos sus personajes, aunque en algún caso no se trata de una muerte física, sino espiritual.

El título del primer cuento de La ciutat i el tròpic, «Suïcidi a la matinada», ya anuncia la muerte desde el principio. El fotógrafo creció rodeado de pobreza 
y de miseria, y trabajó de ayudante de un marmolista de lápidas, de fabricante de ataúdes y de florista de coronas funerarias. Su juventud estuvo ligada a la muerte. El joven siente una gran necesidad de exteriorizar su creatividad, pero carece de oportunidades y de una formación adecuada. Cuando casualmente ejerce como fotógrafo y encuentra a Diego Rivera, emprende la tarea de matar la belleza, ya que es incapaz de crearla, disfrutarla o moldearla a su antojo. El artista mexicano agrava aún más el bajo concepto que el fotógrafo tiene de sí mismo. Las instantáneas de su cámara se convierten en pedazos de realidad muerta, y desde ese momento se dedica a matar todo aquello que no puede alcanzar, asumir, canalizar. El fotógrafo confiesa las similitudes de las dos máquinas, la cámara y la pistola, ya que ambas sirven para matar, y su intención de suicidarse queda reflejada: «Sóc un cadáver: què em deté de fer-me l'autoretrat?».

«El centaure i el cavaller» puede clasificarse como una pequeña novela corta que gira en torno a la justificación de un crimen motivado por la influencia del trópico sobre el hombre occidental. La muerte de los padres del joven protagonista marca su infancia, y acelera su decisión de emigrar a México. Su primer encuentro con la muerte en el país mexicano tiene lugar ante la amenaza de unos soldados. El futuro picador les hace frente al recordar las palabras de un familiar suyo que era militar: «Morir és com retratar-se, [...] quan arriba el moment, el més assenyat és procurar quedar bé». Esta frase resume la importancia de mantener la dignidad ante la muerte, obviando el hecho de morirse. A lo largo de la narración, aparecen los factores que propician el desenlace final. Matar por el amor de una mujer es un viejo tópico, al igual que deshacerse de un rival profesional, que en este caso, además, es un rival sentimental. La muerte en este cuento tiene una función liberadora para todos: el picador protege su negocio y consigue a la mujer que ama, quien se libera de la opresión de su marido; y con respecto al asesinado, se ejerce con él la justicia poética que castiga las malas acciones.

«La lletra» es el ejemplo de muerte en el sentido práctico de la vida. No se trata de una muerte física, sino espiritual. Muere una etapa de frustraciones, de pobreza y de desilusiones. El padre entierra su carácter dependiente y subordinado, acentuado por las humillaciones de su esposa, y nace la iniciativa en él. Se produce un despertar a la vida, una vez se ha dejado atrás un pasado tormentoso, lleno de miserias y tristeza, que resume esta frase: «Érem una gent molt pobra. La misèria ens tractava de tu». El renacer tiene lugar tras haber tocado fondo. La esperanza de una vida mejor, en este caso, provoca que padre e hijo se sobrepongan ante la adversidad cuando encuentran el negocio en liquidación al llegar a México, y hagan uso de una iniciativa que surge tras haber experimentado una muerte psicológica y liberadora.

La trivialidad de la muerte también es habitual en los cuentos de Ferran de Pol. En «Jungla» el asesinato es la consecuencia del caos democrático y político de un país sometido a mandatos caciquiles; a su vez, literariamente, el asesinato ocupa un plano narrativo de importancia similar a la narración del protagonista, quien acaba de pelearse con su novia. El escritor catalán recurre así al absurdo para escenificar esta situación. Este contraste acentúa la tesis de la frecuencia y de la inutilidad de las muertes en tierras mexicanas, que Aub parodia en Crímenes ejemplares. Del mismo modo, la muerte pasa a ser una preocupación menor 
en el narrador, a quien no le preocupa la acusación de asesinato, obsesionado como está con no llamar a su novia. Tras ser detenido, piensa: «Almenys no trucaré a la Lupe: jo seré el més fort!».

«Naufragis» es el cuento que más incorpora la presencia de la muerte. Las fiebres amarillas que merman la población indígena impregnan de muerte todos los caminos. Los cadáveres invaden las calles, al igual que el olor de los muertos quemados. Todo es muerte y destrucción, pero el médico parece ser inmune a ello. La joven francesa, casada con un indio agonizante, devuelve al pregraduado a la realidad, pero este no asimila la situación del país, sino que adquiere derechos sobre la mujer. Incluso desea decirle al indio muerto: «Tu ets mort, ben mort, ho eres des que et vaig posar l'ull a sobre, però la teva dona viu, la teva dona i jo... I ella i jo, saps?, hem vingut d'allà...». El respeto al duelo y al luto se refleja en la población autóctona, que mira con recelo a los médicos occidentales porque no les dejan velar a sus muertos. Pero la muerte de un ser querido es una tradición que el médico no respeta en el velatorio del indio al querer relacionarse con su mujer; y su actitud le condenará al destierro, en una tierra que ya no era la suya, y donde le espera una muerte en vida.

Crímenes ejemplares es una recopilación de anécdotas que emplean el tema de la muerte para reflexionar sobre la intolerancia. Todas las narraciones giran en torno a la muerte. El propio título es un anticipo de lo que Aub pretende representar. Todos los microrrelatos están impregnados de muerte de una forma o de otra: los crímenes son muertes violentas; los suicidios, también; y los epitafios son un resumen de la vida de los muertos.

La muerte, según los personajes de Aub, es una acción justificada en la que los culpables no son los asesinos, sino los asesinados. Las actitudes de estos últimos son las que provocan la iracundia de hombres y mujeres impacientes sin escrúpulos que no son conscientes de su culpabilidad y que actúan con total normalidad. La muerte en Crímenes ejemplares es sinónimo de justicia, y los asesinos son justicieros que administran sus propias leyes. Así, los protagonistas y narradores de Crímenes ejemplares justifican sus actos en todo momento y, además, buscan la complicidad y la comprensión del lector o del juez:

LO MATÉ porque no pude acordarme de cómo se llamaba.

ME SUICIDO por gusto de hacerlo.

LA MATÉ por no darle un disgusto.

Me la devolvió rota, señor.

¡La nuez!, señor juez, ¡la nuez tan sólida, tan mal afeitada, con esa piel de gallina vieja, desplumada y papandujante [...]!

Max Aub elabora un repertorio de muertes gratuitas, exageradas y absurdas, con la intención de llamar la atención sobre la intransigencia, los fanatismos, la violencia, la agresividad y las actitudes intolerantes. Para ello, todas las muertes y suicidios cuentan con un tono de sátira que invita a la reflexión, ante la falta de un contexto narrativo:

«PUDE DAR VIDA, luego me la puedo quitar. Que los mantenga su abuela». 
Los epitafios son un buen ejemplo del humor llevado hasta las últimas consecuencias. Si los microrrelatos ya eran breves, los epitafios concentran en sus breves líneas la ironía de los juegos lingüísticos del autor:

De Don Juan:

Mató a quien quiso.

A modo de reflexión, hemos visto que Ferran de Pol incorpora la muerte en su obra como consecuencia de las influencias del trópico en sus protagonistas ( «El centaure i el cavaller»), como renacimiento vital («La lletra»), como injusticia política («Jungla»), como frustración existencial («Suïcidi a la matinada») o como puente que une o separa culturas enfrentadas («Naufragis»). Y Aub, por su parte, recopila todo un anecdotario mortuorio para mostrar, en tono irónico y haciendo uso del absurdo, la mediocridad del hombre que no es capaz de contener sus instintos y que no distingue entre el bien y el mal. Los personajes de Ferran de Pol sufren cambios de personalidad ante la asfixia que les produce la tierra mexicana. Los de Aub son víctimas de sus manías y obsesiones, y cometen asesinatos al no controlar sus impulsos, como sucede en La ciutat i el tròpic. Sin embargo, en Crímenes ejemplares se advierte la ausencia generalizada de arrepentimiento o culpa - excepto en algunos cuentos-, cuya presencia sí se constata en la obra de Ferran de Pol («El centaure i el cavaller»), aunque también hay crímenes impunes («Jungla»).

La muerte, en la obra de Ferran de Pol, parece actuar como consecuencia de unas circunstancias adversas, al igual que en los cuentos de Aub, cuyas razones se explican en cada microrrelato, a pesar de ser absurdas. En ambos casos, la muerte comporta la eliminación de un obstáculo de tipo amoroso, laboral, o simplemente social. En el México de Ferran de Pol y Aub, la muerte en forma de crimen sirve para vengarse y para administrar justicia («El centaure i el cavaller» y algunos crímenes de Aub); en otras ocasiones, la muerte de alguien allana el camino a los vivos («Naufragis»). Ambos escritores emplean la muerte como nexo, como contexto o como consecuencia, pero en todos los casos esta cumple una función, e incluso se revela útil para algunos personajes. La muerte les acerca al lector, y este los analiza, estudia sus miserias y su psicología. En las dos obras, la muerte une y separa a los personajes y a las culturas opuestas, y su importancia radica en la dualidad de su aparición.

\section{LA DUALIDAD HUMANA}

El análisis de la dualidad del comportamiento humano cierra la estructura triangular aplicada a este estudio, una vez se han tratado la influencia de México y de la muerte en las dos obras comentadas. Max Aub y Lluís Ferran de Pol utilizan el contrapunto en sus cuentos y sitúan a sus personajes en una dicotomía, que habitualmente resuelven sin demasiado éxito. La cultura mexicana les absorbe o influye en su comportamiento, y el trópico hace aflorar sus instintos más primarios.

La estructura de La ciutat i el tròpic se construye alrededor de oposiciones binarias. El propio título ya expresa el contraste alrededor del cual giran los 
cuentos. El trópico se identifica con México, la naturaleza, la barbarie, la irracionalidad y la muerte. La ciudad es el símbolo del mundo europeo occidental, y representa la organización, la cultura, la civilización, la racionalidad y la vida. Sin embargo, todos estos tópicos poseen matices y Ferran de Pol juega a darles la vuelta. Así, cada dualidad encierra otra a su vez, y los personajes parecen no poder escapar de ellas.

La primera dualidad a la que se enfrenta el fotógrafo en «Suïcidi a la matinada» es la de vivir escapando a la muerte. Su vocación de grabador de lápidas y la miseria que le rodea contrasta con la rapidez con la que su madrastra tiene hijos a razón de uno por año. La muerte y la vida viven en la misma casa. Su huida le lleva a emprender un camino de autodestrucción, marcado por dualidades constantes que él no sabe resolver: el robo de la cámara le convierte en fotógrafo; su encuentro con Diego Rivera le hunde en el fracaso y le conduce hacia un éxito repentino que no es capaz de asimilar; la pistola y la cámara comparten la cualidad de matar la realidad; el fotógrafo es admirado pero está profundamente decepcionado con su vida.

Las dualidades que Ferran de Pol introduce en «El centaure i el cavaller» aparecen a lo largo de todo el cuento. El protagonista se siente dividido entre sus dos vocaciones frustradas: los caballos y las antigüedades; y al emigrar a México podrá satisfacer ambas, aunque con resultado desigual. Su trabajo como picador culmina su amor por los caballos. Y el recién llegado picador es un militar que encarna al centauro: un ser mitológico y una joya preciada de anticuario, al igual que su mujer, cuyo rostro compara con la porcelana. La tensión se resuelve de una forma igualmente dual: el joven asesina al picador para liberarse de una amenaza que desestabiliza su situación personal y profesional. Las circunstancias le han hecho cometer un crimen que ni tan siquiera él se explica, y desde la prisión reconoce: "Voler i doldre és la meva mateixa naturalesa».

La dualidad acción-inacción marca el ritmo de «La lletra». El joven anhela que su padre tome la iniciativa y viva lejos de la miseria y del desprecio de su segunda mujer; y así, superada la pasividad, ambos emprenden el viaje rumbo a México. La carta de recomendación de un amigo es el punto de partida de su aventura mexicana, aunque el resultado final será agridulce y a su llegada se encuentran con un negocio en plena liquidación. La carta (la lletra) que tan celosamente guardaba el hijo durante el viaje no ha servido para darles trabajo, pero sí para decantar la balanza de la dualidad actividad-pasividad a favor de la primera.

Por otro lado, en «Jungla» Ferran de Pol introduce una dualidad narrativa, además de las dualidades argumentales. Las circunstancias de los dos periodistas - el que ha roto con su pareja y el que critica la situación política - se entrelazan durante la narración y comparten protagonismo. Resulta grotesca la mezcla de un desengaño sentimental con la preocupación política. Lo absurdo de la situación sirve para poner de manifiesto la realidad política corrupta del país mexicano. El narrador-periodista continúa con su obsesión sentimental, mientras que su compañero denuncia el caciquismo del país y muere injustamente a manos de un diputado. En este caso, la muerte de una persona recibe el mismo tratamiento narrativo que un enfado de enamorados; y el personaje principal cae a 
manos de la irracionalidad cuando, en su estado de división interna muerte-enfado, prefiere el enfado.

En «Naufragis», Ferran de Pol juega con el desarraigo para ambientar la dualidad humana en un terreno inhóspito y en circunstancias extremas. En primer lugar, el protagonista es médico sin serlo. La guerra no le permitió graduarse y, a pesar de su profesionalidad, las denuncias de sus propios compañeros le obligarán a exiliarse dentro de su exilio con un cartel que dice «Ejerce sin título», otra contradicción. La mujer francesa le trae recuerdos de sus orígenes, y a lo largo de la narración serán constantes las referencias al aquí y al allí, propias de una persona dividida. La integración del personaje en tierras mexicanas no acaba de producirse nunca, pero en este caso — otra dualidad - cabe recordar que son los occidentales, y no los indígenas, quienes condenan al médico a un nuevo naufragio en México.

Volviendo a Max Aub, la condición dual humana queda reflejada a la perfección en el título de su obra: Crímenes ejemplares. Esta colección de microrrelatos narra el comportamiento bárbaro de la humanidad a través de personas de aparente normalidad, orgullosas de sus actos y complacidas con la justicia que imparten. Los crímenes de Aub, lejos de ser modelos a seguir, evidencian la mediocridad del género humano.

Para ello, su autor recurre al equívoco, a la ironía, al contraste, a la ambigüedad, al juego de palabras, a la hipérbole y, sobre todo, a la elipsis. El dominio lingüístico del escritor produce sorpresa en un lector que se encuentra directamente con la confesión del asesino. En muchas ocasiones, lo más importante es lo que no se narra, lo que no se escribe, lo que se omite. La dualidad que utiliza Aub se mueve entre lo narrado - que es brevísimo- y lo omitido — que es mucho-, y se apoya, además, en el uso de la ironía para concentrar en pocas palabras la brutalidad de un asesinato. A pesar de las constantes elipsis, el lector es capaz de guiarse entre los relatos, y la brevedad de los cuentos causa un golpe de efecto en él que le hace ser consciente de la dimensión trágica de cada escueta frase.

Asociada a la elipsis, la brevedad es una constante en los cuentos de Aub, en contraposición a los de Ferran de Pol. El microrrelato « ¡TENíA EL CUELLO tan largo!» es impactante por su brevedad, y el lector sabe que se trata de un crimen porque está incluido en una recopilación de crímenes. Aub concentra en cinco palabras toda una vida $-\mathrm{y}$ una muerte - , haciendo uso de una dualidad que consiste en aplicar la brevedad lingüística a una narración completa, cuya información se extrae de forma extralingüística (introducción, trama, personajes, desarrollo...).

En Crímenes ejemplares el asesino es una víctima antes que un criminal. Esta dualidad es una de las favoritas del escritor, y aparece en todos los cuentos. Aub revierte los roles de los personajes y siembra la confusión al intercambiar sus papeles. Los asesinos lo son porque matan, pero también se muestran como víctimas, y dentro de estas hay varios subtipos. En algunos casos, los criminales son víctimas de sus impulsos, y a veces muestran su arrepentimiento: «No lo hice adrede»; «Yo no quise darle tan fuerte». En otras ocasiones, la dualidad asesino-víctima se expresa en otros términos, de manera que el criminal es una víc- 
tima de la ineptitud, del comportamiento insoportable de los futuros asesinados, del aburrimiento, de su falta de voluntad o de su irracionalidad:

FUE POR PURA tozuda. No le costaba nada hacerlo.

¡ME NEGÓ que le hubiera prestado aquel cuarto tomo....!

LO MATÉ porque bebí lo justo para hacerlo.

Lo maté porque me lo dijo mi mamá.

¿USTED NO HA MATADO NUNCA a nadie por aburrimiento, por no saber qué hacer? Es divertido.

La dualidad asesino-víctima se invierte en los microrrelatos de Aub, y el criminal se ve sometido a una variedad de circunstancias. La dualidad muerte-justicia es otra de las más recurrentes en la obra. El asesino no solo está contento por su acción, sino que interactúa con el lector para convencerle de lo acertado de su decisión:

¿USTEDES NO HAN TENIDO nunca ganas de asesinar a un vendedor de lotería, cuando se ponen pesados, pegajosos, suplicantes? Yo lo hice en nombre de todos.

El empleo de la lógica alcanza incluso el racionalismo cartesiano en uno de los crímenes barrocos, donde la dualidad entre pensamiento y existencia se retuerce hasta lo infinito, y permite al asesino justificar una vez más su crimen mediante la ambigüedad:

No existo porque pienso ni pienso porque existo. [...] Si para vivir se necesitara pensar, estábamos lúcidos. Pero, en fin, si ustedes están convencidos de que así es, soy inocente, totalmente inocente ya que no pienso ni quiero pensar. Luego si no pienso no soy y si no soy ¿cómo voy a ser responsable de esa muerte?

Mientras Aub juega más con las dualidades sobre la muerte (muerte-vida), Ferran de Pol se centra en las de México (trópico-civilización). Por último, en Crímenes ejemplares, el humor aubiano contrasta con la gravedad del tema asesinatos y suicidios - y también funciona como dualidad. El tono empleado por el escritor obedece a un doble propósito: desdramatizar una tragedia - la muerte en cualquiera de sus formatos-y hacernos conscientes de la gravedad de los hechos narrados a través de la ironía. Este ejemplo es muy ilustrativo:

¿QuÉ CULPA tengo, señor, de que el machete estuviese bien afilado? Fue casualidad. Por eso no se castiga a nadie [...].

\section{CONCLUSIONES}

En la brevedad de los cuentos de La ciutat i el tròpic, el escritor catalán concentra su experiencia personal en México, y experimenta con las técnicas na- 
rrativas de la novela psicológica y existencialista, partidarias de una profunda construcción de los personajes. El argumento queda relegado a un segundo plano y sirve para contextualizar el choque de culturas, el rechazo a la realidad y la evasión del personaje en una tierra extraña. La narración es directa y fluida y se lleva a cabo a través de los protagonistas. El uso de la simbología es constante y se centra principalmente en la mitología. El fatalismo, la angustia y la autodestrucción del hombre sometido a oposiciones binarias son los principales puntos que se desarrollan en los cuentos; y parece inevitable para el lector quedarse con la impresión de que México es el reflejo de las peores pesadillas del hombre occidental. Sin embargo, Ferran de Pol no emite juicios morales ni valoraciones culturales, sino que transmite su propia experiencia a través de unos personajes desarraigados, alienados, abandonados a su suerte, obligados a adaptarse sin éxito a unas circunstancias extremas y rodeados de muerte.

Crímenes ejemplares conjuga el uso del absurdo con lo grotesco de una realidad más real que imaginaria. El uso de la sentencia, del aforismo, del epitafio o del microrrelato enmascara la tragedia de la muerte y ridiculiza a una raza humana que atropella el uso de toda lógica y abandera la sinrazón. La ausencia de narración, de contexto o de diálogo crea esa fórmula particular aubiana que convierte al autor de los crímenes en un maestro de la concisión y de la precisión. Tampoco Aub apela a nuestra moralidad; ni siquiera él manifiesta la suya. En Crímenes ejemplares existen jueces, pero no juicios; y los roles de los juzgados aparecen invertidos. Los personajes, además de ser conscientes de sus actos, son consecuentes con ellos. Y el único gobierno que conocen es la irracionalidad.

En un período en el que las guerras y los exilios marcan el ritmo de la historia, la muerte se convierte en un trasfondo literario inevitable, que suele acompañarse de un replanteamiento de la vida y de las propias convicciones. Debe recordarse que en Ferran de Pol se ha visto una inquietud existencial que lo envuelve todo de angustia, mientras que Aub disfraza esa misma preocupación con dosis de humor negro e ironía. Los personajes de La ciutat i el tròpic huyen de sí mismos, ya que no desean reconocer su fracaso personal o profesional. Los de Crímenes ejemplares resuelven sus conflictos internos mediante el asesinato o el suicidio.

En algún momento de sus vidas, todas las personas se ven obligadas a escoger. La elección es un acto que implica renuncia, y no siempre se acierta con lo elegido. En algunas ocasiones, el peso de aquello a lo que han renunciado es mayor que lo escogido. En otras, las consecuencias de dicha elección marcan su destino y las rodean de melancolía y fatalismo. Y es que la vida es un camino de dualidades, y así se ha visto reflejado en las dos obras comentadas. El origen de la división interior que manifiestan Aub y Ferran de Pol en su literatura radica en sus exilios mexicanos, motivados por la guerra española de 1936. A su vez, México es el origen de las dualidades humanas de los personajes de La ciutat i el tròpic $\mathrm{y}$, por otro lado, la muerte actúa como consecuencia de la ambigüedad del hombre en Crímenes ejemplares.

Este estudio no pretende exponer una visión maniquea de las obras seleccionadas. La dualidad, es cierto, se debate entre dos polos opuestos, pero estos deben observarse desde múltiples puntos de vista, articulados, en todo caso, por 
los otros dos elementos que conforman la estructura triangular propuesta. Es decir, México, la muerte y las dualidades son una misma cosa: origen y consecuencia unos de otros.

Para finalizar, se cita un ejemplo de Crímenes ejemplares que resume la esencia misma de la condición dual del hombre, de la intolerancia, del desconocimiento, del miedo al otro y de la mediocridad:

LO MATÉ porque no pensaba como yo.

\section{BIBLIOGRAFÍA}

Arranz Lago, D. F. (2003): «Indagaciones lingüísticas en Crímenes ejemplares de Max Aub», Congreso Internacional del Centenario «Max Aub, testigo del siglo XX», Valencia. <http://www.uv.es/entresiglos/max/pdf/david\%20felipe\%20arranz.pdf $>$ [Última consulta: 20 de mayo de 2011].

Aub, M. (1957, 1999): Crímenes ejemplares, Madrid, Espasa Calpe.

Aznar Soler, M. (2003): «Max Aub», Boletín Informativo. Fundación Juan March, 326, pp. 3-12.

Busquets i Grabulosa, Ll. (1979): «Lluís Ferran de Pol, de prop i de lluny», El Correo Catalán (06/10/79).

Calles, J. M. (2003): «Un cierto Max Aub», Espéculo, 23. $<$ http://www.ucm.es/info/especulo/numero23/m_aub.html> [Última consulta: 20 de mayo de 2011].

Castellanos, J. (1995): «Pròleg. Ferran de Pol, entre la ciutat i el tròpic», en Lluís Ferran de Pol (1956): La ciutat i el tròpic, Barcelona, Curial, pp. 5-26.

Del Villar, A. (2003): «Max Aub, cronista de la República», Cuadernos republicanos, 53, pp. 91-107.

Eagleton, T. (1988): Una introducción a la teoría literaria, Madrid [etc.], Fondo de Cultura Económica.

Ferran de Pol, L. (1956, 1995): La ciutat i el tròpic, Barcelona, Curial.

García i Raffi, J.V. (1998): «Cavalleresca catalana: notes sobre un text inèdit de Lluís Ferran de Pol», Tirant, 1. <http://parnaseo.uv.es/Tirant/Art.Ferran_de_Pol.html> [Última consulta: 20 de mayo de 2011].

García Sánchez, F. (2006): «Estudio introductorio. Fábulas de vanguardia y ciertos cuentos mexicanos», en Oleza Simó, J. (dir.), Max Aub. Obras completas. Relatos I. Fábulas de vanguardia y ciertos cuentos mexicanos, vol. IV - A, Valencia, Generalitat Valenciana, p. 21.

González Fuentes, J. A. (1997): «Crímenes ejemplares de Max Aub», Clarín, año 2, 11, pp. 76-77. 
Guillén, C. (2005): Entre lo uno y lo diverso. Introducción a la literatura comparada (ayer y hoy), Barcelona, Tusquets.

Hernández Cuevas, J. C. (2004): «Los cuentos mexicanos de Max Aub», Ciberletras, 12.

Oleza Simó, J. (director) (2006): Max Aub. Obras completas. Relatos I. Fábulas de vanguardia y ciertos cuentos mexicanos, vol. IV - A, Valencia, Generalitat Valenciana.

Platón (1991) Obras completas, Madrid, Aguilar.

Ramos, S. (1963): El perfil del hombre y la cultura en México, México, UNAM.

Sánchez Zapatero, J. (2007): «México en la obra narrativa de Max Aub», Espéculo, 35. <http://www.ucm.es/info/especulo/numero35/mexiaub.html> [Última consulta: 20 de mayo de 2011].

Tejada Tello, P. (2006): «Crímenes ejemplares de Max Aub y el cine», Espéculo, 32. <http://www.ucm.es/info/especulo/numero32/crejempl.html> [Última consulta: 20 de mayo de 2011].

Tejada Tello, P. «Crímenes ejemplares: Humor y 'más aún’»:

$<\mathrm{http}: / /$ www.uv.es/entresiglos/max/pdf/crimenes\%20ejemplares.pdf> [Última consulta: 20 de mayo de 2011].

Revista UOC, «Cataluña desde los trópicos»:

$<$ http://www.uoc.edu/lletra/exili/esp/noms/lferrandepol/index.html> [Última consulta: 20 de mayo de 2011]. 